\title{
Persistent Reversal of Enhanced Amphetamine Intake by Transient CaMKII Inhibition
}

\author{
Jessica A. Loweth, ${ }^{1,2}$ Dongdong Li, ${ }^{2}$ James J. Cortright, ${ }^{2}$ Georgia Wilke, ${ }^{2}$ Okunola Jeyifous, ${ }^{3}$ Rachael L. Neve, ${ }^{4}$ \\ K. Ulrich Bayer, ${ }^{5}$ and Paul Vezina ${ }^{1,2}$ \\ ${ }^{1}$ Committee on Neurobiology, and Departments of ${ }^{2}$ Psychiatry and Behavioral Neuroscience and ${ }^{3}$ Neurobiology, The University of Chicago, Chicago, Illinois \\ 60637, ${ }^{4}$ Massachusetts Institute of Technology, Cambridge, Massachusetts 02139, and ${ }^{5}$ Department of Pharmacology, University of Colorado Denver, \\ Aurora, Colorado 80045
}

Amphetamine exposure transiently increases $\mathrm{Ca}^{2+} /$ calmodulin-dependent protein kinase II (CaMKII) $\alpha$ expression in the nucleus accumbens (NAcc) shell and this persistently increases local GluA1 S831 phosphorylation and enhances behavioral responding to the drug. Here we assessed whether transiently interfering with CaMKII signaling using a dominant-negative CaMKII $\alpha$ mutant delivered to the NAcc shell with herpes simplex viral vectors could reverse these long-lasting biochemical and behavioral effects observed following exposure to amphetamine. As expected, transient expression of CaMKII $\alpha$ K42M in the NAcc shell produced a corresponding transient increase in CaMKII $\alpha$ and decrease in pCaMKII $\alpha$ (T286) protein levels in this site. Remarkably, this transient inhibition of CaMKII activity produced a long-lasting reversal of the increased GluA1 S831 phosphorylation levels in NAcc shell and persistently blocked the enhanced locomotor response to and self-administration of amphetamine normally observed in rats previously exposed to the drug. Together, these results indicate that even transient interference with CaMKII signaling may confer long-lasting benefits in drug-sensitized individuals and point to CaMKII and its downstream pathways as attractive therapeutic targets for the treatment of stimulant addiction.

\section{Introduction}

Previous exposure to psychostimulants such as amphetamine and cocaine enhances subsequent neurochemical and behavioral responding to the drug. These phenomena are thought to contribute to the transition from casual drug use to addiction (Robinson and Berridge, 1993; Vezina, 2004). A brain area prominently linked to the generation of addictive behaviors is the nucleus accumbens (NAcc) shell (Anderson et al., 2008). We recently showed that amphetamine exposure transiently increases expression of the $\mathrm{Ca}^{2+} /$ calmodulin-dependent protein kinase II (CaMKII) $\alpha$ isoform in this site and that transient viral overexpression of CaMKII $\alpha$ mimics the behavioral effects of amphetamine exposure in rats (Loweth et al., 2010). Conversely, NAcc shell infusion of a CaMKII inhibitor (KN93) prevents cocaine-induced reinstatement of drug seeking (Anderson et al., 2008), as well as the expression of enhanced NAcc dopamine overflow (Pierce and Kalivas, 1997), cocaine-induced locomo-

\footnotetext{
Received Sept. 13, 2012; revised 0ct. 25, 2012; accepted Nov. 24, 2012.

Author contributions: J.A.L. and P.V. designed research; J.A.L., D.L., J.J.C., G.W., and 0.J. performed research; R.L.N. and K.U.B. contributed unpublished reagents/analytic tools; J.A.L. and P.V. analyzed data; J.A.L., K.U.B., and P.V. wrote the paper.

This study was supported by grants from the Peter F. McManus Charitable Trust (P.V.), as well as National Institutes of Health Grants R01 DA09397 (P.V.), R01 NS052644 (K.U.B.), T32 DA07255 (J.J.C. and 0.J.), and F31 DA022834 (J.A.L).

The authors declare no competing financial interests.

Correspondence should be addressed to Paul Vezina, Department of Psychiatry and Behavioral Neuroscience, The University of Chicago, 5841 South Maryland Avenue, MC 3077, Chicago, IL 60637. E-mail: pvezina@yoda.bsd.uchicago.edu. For information regarding CaMKII mutant biochemistry: K. Ulrich Bayer. E-mail: ulli.bayer@ucdenver.edu.

DOI:10.1523/JNEUROSCI.4386-13.2013

Copyright $\odot 2013$ the authors $\quad 0270-6474 / 13 / 331411-06 \$ 15.00 / 0$
}

tion (Pierce et al., 1998), and amphetamine self-administration (Loweth et al., 2008), normally observed in sensitized rats. However, KN93 affects not only CaMKII and other protein kinases, but also L-type $\mathrm{Ca}^{2+}$ channels (Li et al., 1992; Gao et al., 2006), and an inhibitor of these channels produces the same biochemical (Pierce and Kalivas, 1997) and behavioral effects (Pierce et al., 1998; Anderson et al., 2008) as KN93. Furthermore, these studies did not directly assess the possibility that transient NAcc shell CaMKII inhibition could have long-lasting effects on behavioral responding to psychostimulants, a possibility suggested by our earlier work showing that transient increases in CaMKII $\alpha$ in this region lead to long-lasting neuroadaptations that contribute to the maintenance of sensitization (Loweth et al., 2010). Thus, in the present study, we used a CaMKII- and brain region-specific transient inhibition strategy to determine whether interfering directly with endogenous CaMKII signaling within the NAcc shell could persistently reverse long-lasting behavioral manifestations of amphetamine sensitization.

\section{Materials and Methods}

Strategy for CaMKII inhibition by viral-mediated expression of a K42M mutant. Replication-deficient herpes simplex virus (HSV) viral vectors were constructed and packaged as previously described by us (Neve et al., 1997; Loweth et al., 2010). These vectors were used because they produce transient overexpression of the transgene that peaks $3-4 \mathrm{~d}$ post-infection and returns to baseline by day 8 post-infection (Neve et al., 1997; Carlezon and Neve, 2003; Loweth et al., 2010). In addition, local viral infection permits functional testing of specific groups of neurons in specific brain areas (here, the NAcc shell). We chose to transiently express a CaMKII $\alpha$ K42M mutant that is "kinase dead" due to impaired ATP binding. Such kinase-dead mutants are commonly used as "dominant-negative" mu- 
tants to interfere with endogenous kinase functions, and this has been described for CaMKII (e.g., Kühl et al., 2000; Xiao et al., 2005; Garic et al., 2011). Dominant-negative effects can be exerted by competition with endogenous kinase for upstream activators, downstream substrates, or subcellular targeting modules. In the case of CaMKII, which forms dodecameric holoenzymes, dominant-negative effects can also be exerted by the formation of heteromeric holoenzymes, which interferes with the intraholoenzyme inter-subunit autophosphorylation at T286 that generates $\mathrm{Ca}^{2+}$-independent "autonomous" CaMKII activity (for reviews, see Coultrap and Bayer, 2012; Lisman et al., 2012). In addition, the K42M mutant interferes with the targeting of holoenzymes to the NMDA-type glutamate receptor subunit GluN2 (Bayer et al., 2006; O'Leary et al., 2011), which is regulated by nucleotide binding to CaMKII (O'Leary et al., 2011) and also generates autonomous activity (Bayer et al., 2001; Bayer et al., 2006). Thus, the K42M mutant of CaMKII has even greater dominant-negative potential than the kinasedead mutants of most other kinases. The regulation of CaMKII is rather complex (Coultrap and Bayer, 2012), but it should be noted that some cellular functions that simply require $\mathrm{Ca}^{2+}$ / calmodulin-stimulated CaMKII activity may or may not be affected by the presence of additional kinase-dead mutant. Thus, the designation as a dominant-negative mutant (as done here) is always linked to a specific cellular function; for other functions, a particular kinase-dead mutant may or may not act in a dominant-negative fashion (for further discussion, see Wayman et al., 2011).

Subjects and surgery. Male Sprague-Dawley (locomotion experiments) and Long-Evans rats (self-administration experiments) weighing 250-275 g on arrival were purchased from Harlan Sprague-Dawley and housed individually with food and water available ad libitum. They were implanted with chronic bilateral guide cannulae as described previously (Loweth et al., 2010). For the amphetamine self-administration studies, rats were also implanted with intravenous catheters as described previously (Suto et al., 2004). All surgical procedures were conducted using aseptic techniques according to an approved Institutional Animal Care and Use Committee protocol.

Design and procedure. Rats in different groups were exposed to repeated intermittent injections of amphetamine or saline and 2-3 weeks later, infused intracranially into the NAcc shell with HSV-K42M CaMKII $\alpha$ or a control infusion (mock) consisting of HSV-LacZ or 10\% sucrose vehicle. Rats in one experiment were tested for their locomotor response to a systemic amphetamine injection $4 \mathrm{~d}$ and again $8 \mathrm{~d}$ following infection. Rats in a second experiment were tested for their self-administration of amphetamine before and after HSV infection. Rats in additional groups were killed 4 or $8 \mathrm{~d}$ following HSV infection to determine the expression pattern of the transgene and assess its effect on phosphorylation of the AMPA receptor GluA1 subunit at S831, a CaMKII residue. In these cases, brain sections were harvested and subsequently assessed using immunoblotting.

Exposure injections. Exposure injections $(5 \times 1.5 \mathrm{mg} / \mathrm{kg}$ amphetamine or $1.0 \mathrm{ml} / \mathrm{kg}$ saline) were administered every $2-3 \mathrm{~d}$ as described previously (Vezina et al., 2002; Suto et al., 2004). S(+)-amphetamine sulfate was obtained from Sigma-Aldrich and dissolved in sterile saline. Doses refer to the weight of the salt.

Viral-mediated gene transfer in the NAcc shell. The following HSV vector constructs were used: CaMKII $\alpha$ K $42 \mathrm{M}$ and a control vector, LacZ, which
Day 8 Post-Infection
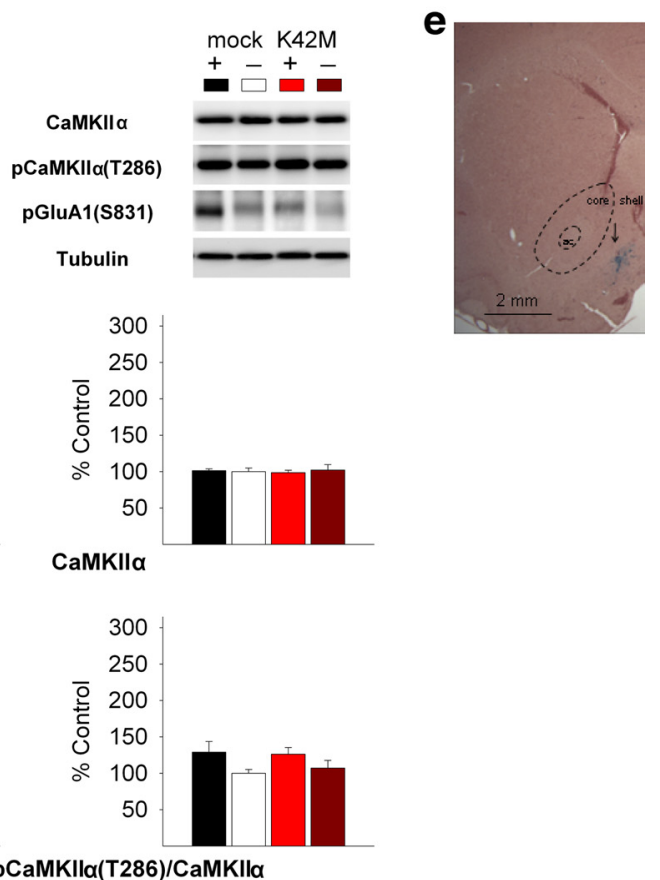

pCaMKIla(T286)/CaMKIla

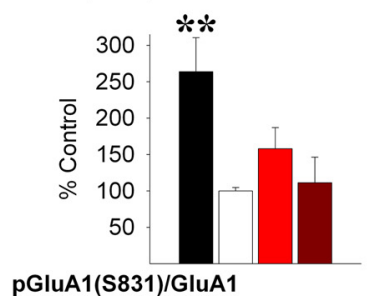

pGluA1(S831)/GluA1

Figure 1. HSV-CaMKII $\alpha$ K42M transiently reduces CaMKII $\alpha$ T286 autophosphorylation but persistently reverses the increased phosphorylation of GluA1 at $\$ 831$ in NAcc shell of amphetamine-exposed rats. $\boldsymbol{a}$, Rats received NAcc shell microinjections of

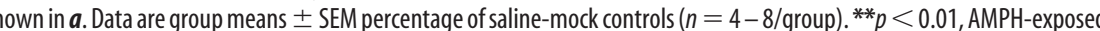
mock-infected versus remaining groups; ${ }^{* * *} p<0.001$, K42M versus mock; by significant ANOVA followed by LSD tests. $\boldsymbol{e}$, Photomicrograph of $\beta$-galactosidase-positive neurons illustrating the site of infection in NAcc shell (arrow).

encodes the protein $\beta$-galactosidase. LacZ and $10 \%$ sucrose vehicle were used interchangeably for mock-infection control infusions as they have consistently been found to be without effect (Loweth et al., 2010; Singer et al., 2010). Rats were transported to a biosafety level 2 facility where, as described previously (Loweth et al., 2010; Singer et al., 2010) and according to an approved Institutional Biosafety Committee protocol, they were administered bilateral intracranial microinjections into the NAcc shell of their respective viral vectors or mock control vehicle. Rats were returned to the colony room $24 \mathrm{~h}$ later.

Locomotor testing. To assess the effect of transient expression of CaMKII $\alpha$ K42M in NAcc shell neurons on sensitized locomotor responding to amphetamine, rats were assigned randomly to different groups based on exposure (systemic amphetamine or saline) and infection (NAcc shell HSV-K42M CaMKII $\alpha$ or mock). Thus, four groups were tested: amphetamine-mock, amphetamine-K42M, saline-mock, and saline-K42M. Two to 3 weeks after the exposure regimen, rats received their respective NAcc shell microinjections and were tested for their locomotor response to amphetamine $(1.0 \mathrm{mg} / \mathrm{kg}$, i.p.) 4 and $8 \mathrm{~d}$ later. On each test day, locomotor activity was measured $1 \mathrm{~h}$ before and $2 \mathrm{~h}$ after the amphetamine challenge injection using a bank of 12 activity boxes as described previously (Vezina et al., 2002).

Self-administration training and testing. To assess the effects of transient expression of CaMKII $\alpha$ K42M on enhanced amphetamine self- 


\section{a Day 4 Post-Infection}

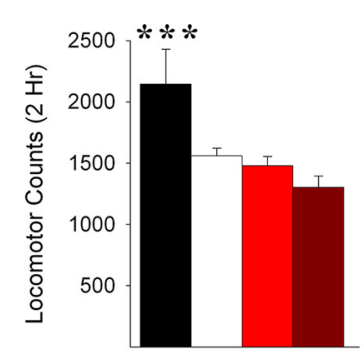

\section{b Day 8 Post-Infection}

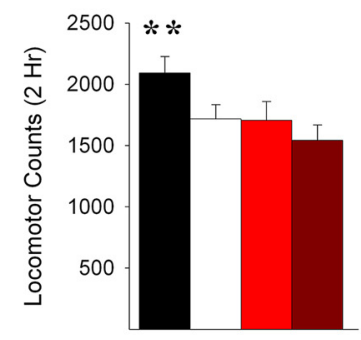

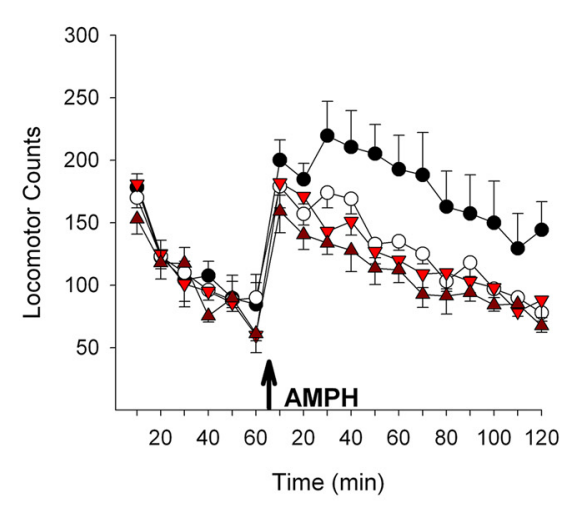

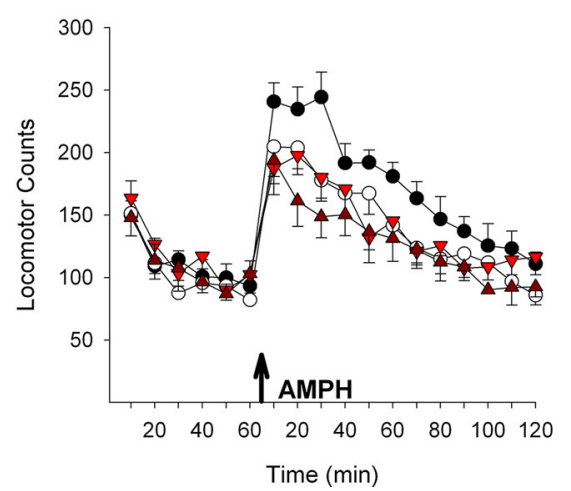

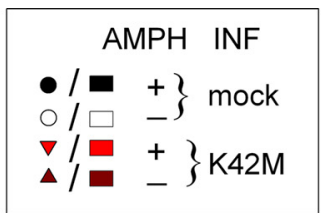

c

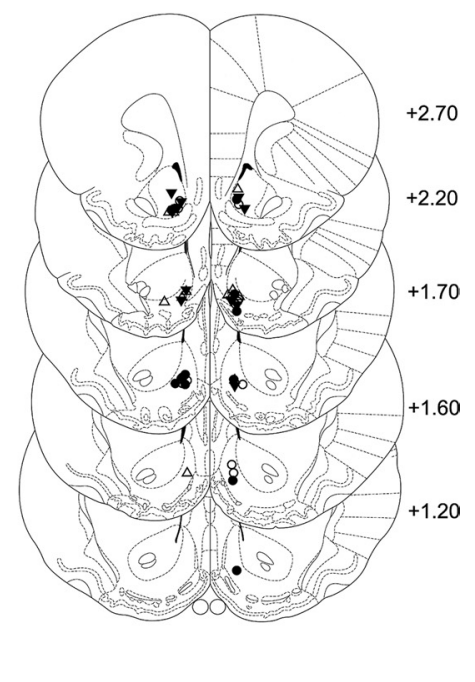

Figure 2. Transient NAcc shell CaMKIl $\alpha$ K42M expression persistently reverses amphetamine-induced locomotor sensitization. $\boldsymbol{a}, \boldsymbol{b}$, Rats were exposed to amphetamine (AMPH) or saline and, 2-3 weeks later, received NAcc shell microinjections of HSV-CaMKIl $\alpha$ K42M or mock-infection (INF) infusions. Locomotor responding to AMPH was assessed when protein levels were elevated (day 4) and once they had dissipated (day 8). Data are shown to the left as group mean ( \pm SEM) $2 \mathrm{~h}$ total locomotor counts following the AMPH injection $4 \mathrm{~d}(\boldsymbol{a})$ and $8 \mathrm{~d}(\boldsymbol{b})$ post-infection. In each case, time courses of the locomotor responses are illustrated to the right as group mean ( \pm SEM) locomotor counts obtained before and after the AMPH injection (arrows). Transient expression of CaMKIl $\alpha$ K42M blocked enhanced AMPH-induced locomotion at both days 4 and 8 post-infection. ${ }^{* *} p<0.01,{ }^{* * *} p<0.001$, AMPH-exposed mock-infected versus remaining groups; by significant ANOVA followed by LSD tests. $n=6-7 /$ group. $c$, Location of the injection cannula tips for rats included in the data analyses. Symbols indicate group affiliation. Line drawings are from Paxinos and Watson (2005). Numbers to the right indicate the number of millimeters from bregma.

administration, separate rats were assigned randomly to one of four groups based on exposure and infection as described above for locomotor testing. Two to 3 weeks after the last exposure injection, rats were trained to selfadminister amphetamine on fixed ratio (FR) schedules of reinforcement and then tested under a progressive ratio (PR) schedule for $4 \mathrm{~d}$ pre-infection to visualize enhanced work output and drug intake in amphetamine-exposed rats (Vezina et al., 2002). The following day, rats were transported to the biosafety facility and administered their respective NAcc shell microinjections. PR self-administration testing resumed the next day and continued for $12 \mathrm{~d}$ post-infection as described previously (Loweth et al., 2010). Reinforced lever presses delivered an infusion of amphetamine (200 $\mu \mathrm{g} / \mathrm{kg} /$ infusion $)$ through the intravenous catheter. Six rats did not satisfy the FR training criteria and were excluded from the study. The daily PR test sessions were terminated after $3 \mathrm{~h}$ or after $1 \mathrm{~h}$ elapsed without a drug infusion.

Immunoblotting and immunohistochemistry. Brains were removed rapidly and flash-frozen on dry ice. Sections ( $1 \mathrm{~mm}$ thick) were obtained with a brain matrix, and 2-mm-diameter punches were taken bilaterally around the injection cannula tips. Tissue punches were processed, loaded (20 $\mu \mathrm{g} / \mathrm{lane})$, run using SDS-PAGE, and developed. The following primary antibodies were used: CaMKII $\alpha$ (1:2000), pCaMKII (T286; 1:1000), GluA1 (1:1000), pGluA1(S831;1:500), and $\beta$-actin $(1: 2000)$ or tubulin $(1: 100,000)$ as a loading control. All antibodies were obtained from Millipore except for $\beta$-actin (Sigma-Aldrich). Additional rats were used in immunohistochemistry studies (infection with HSV-LacZ) to visualize the pattern of infection as described previously (Carlezon and Neve, 2003).

Histology. After the completion of the behavioral experiments, rats were deeply anesthetized and perfused transcardially with $0.9 \%$ saline and $10 \%$ formalin, and brains were removed and stained with cresyl violet to identify rats with injection cannula tips located bilaterally in the NAcc shell. Only rats with both cannula tips in the targeted region were retained for statistical analyses, and their number subsequently indicated as n/group in the appropriate figure legends. The number of rats that failed to meet this criterion for the locomotor and self-administration studies was as follows: amphetaminemock, 7; amphetamine-K42M, 5; saline-mock, 2; saline-K42M, 3.

Data analysis. Immunoblot, locomotor, and self-administration data were analyzed with two-way between ANOVA with exposure (amphetamine and saline) and infection (HSV-CaMKII $\alpha$ K42M and mock) as the between factors. Post hoc comparisons were made using the least significant difference (LSD) test. For locomotion, the data analyzed were the total locomotor counts obtained following the amphetamine challenge $(2 \mathrm{~h})$ on each test day. For self-administration, the data analyzed were the total number of infusions obtained on day -1 pre-infection, on day 4 post-infection (when expression of the transgene was maximal), and averaged over days $8-12$ post-infection (when the transgene was no longer expressed).

\section{Results}

Transient CaMKII inhibition persistently reverses increased GluA1 S831 phosphorylation in the NAcc shell of amphetamine-exposed rats

HSV vectors were used to transiently overexpress an inactive mutant of CaMKII $\alpha$ (K42M) in NAcc shell neurons (Fig. 1e) as we have previously described for active CaMKII $\alpha$ (Loweth et al., 2010). Two to 3 weeks after exposure to amphetamine or saline, rats received 
bilateral NAcc shell microinjections of HSV-CaMKII $\alpha$ K $42 \mathrm{M}$ or mock-infection control infusions. CaMKII $\alpha$ protein and T286 phosphorylation levels were assessed on days 4 and 8 post-infection (Fig. $1 b, c$ ). Consistent with previous findings (Loweth et al., 2010), no changes in either CaMKII $\alpha$ protein or T286 phosphorylation levels were detected 2-3 weeks after exposure to amphetamine as displayed in the mockinfected rats. Subsequent infection with HSV-CaMKII $\alpha$ K42M transiently increased total CaMKII $\alpha$ protein levels in both amphetamine- and saline-treated rats; these returned to baseline levels by day 8 postinfection (Fig. 1b). In contrast, T286 phosphorylation was transiently decreased, both in absolute terms (data not shown) and as a ratio of phospho-T286 to total CaMKII $\alpha$ (Fig. 1c), confirming that expression of $\mathrm{CaMKII} \alpha \mathrm{K} 42 \mathrm{M}$ interfered with endogenous CaMKII signaling. This effect was also transient and no longer evident by day 8 post-infection (Fig. 1c). The ANOVA conducted on CaMKII $\alpha$ levels and the ratio pCaMKII $\alpha / \mathrm{CaMKII} \alpha$ showed significant effects of infection only on day 4 postinfection $\left(F_{(1,19)}=20.12, p<0.001\right.$ and $F_{(1,19)}=15.90, p<0.001$, respectively). No other effects, including on day 8 postinfection, were statistically significant. Thus, transient viral expression of CaMKII $\alpha$ K $42 \mathrm{M}$ transiently interfered with "autonomy"-inducing CaMKII T286 phosphorylation, which was back to control levels on day 8 post-infection.

As exposure to a sensitizing amphetamine regimen leads to a long-lasting increase in phosphorylation of GluA1 at S831 in the NAcc shell (Loweth et al., 2010), we then assessed the effect of transiently inhibiting CaMKII signaling in this site on phosphorylation of this GluA1 residue. Again, a sustained increase in GluA1 S831 phosphorylation was detected in the NAcc shell of mock-infected rats 2-3 weeks after exposure to amphetamine. This increase in phospho-S831 was reversed by CaMKII $\alpha$ K42M expression on day 4 (infection, $F_{(1,17)}=5.70$, $p<0.05$ ), and, remarkably, remained attenuated on day 8 postinfection (exposure, $F_{(1,18)}=10.99, p<0.01$ ) when both CaMKII $\alpha$ expression and T286 phosphorylation had returned to baseline levels. No other effects were statistically significant. These findings were again observed both in absolute terms (data not shown) and as a ratio of phospho-S831 to total GluA1 (Fig. 1d).

Transient CaMKII inhibition in the NAcc shell of amphetamine-exposed rats persistently reverses their enhanced locomotor response to and self-administration of the drug

As expected, rats exposed to amphetamine 2-3 weeks earlier showed a greater locomotor response to a systemic amphetamine challenge $(1.0 \mathrm{mg} / \mathrm{kg}$, i.p.) compared with saline-exposed controls (Vezina, 2004) (Fig. 2). Remarkably, transient CaMKII inhibition in the NAcc shell persistently reversed this expression of locomotor sensitization by amphetamine. The enhanced loco-
C

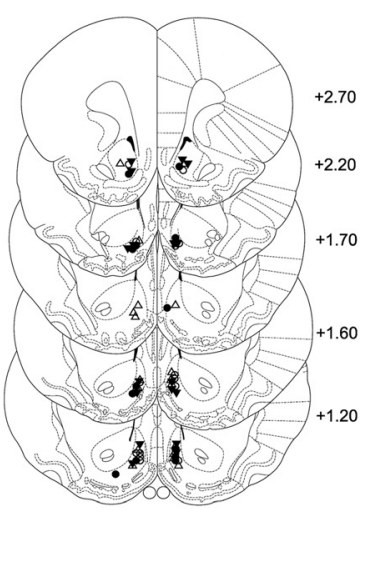

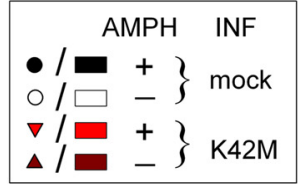

Figure 3. Transient CaMKII inhibition in the NAcc shell of amphetamine-exposed rats persistently reverses enhanced amphetamine $\alpha$ K42M or mock infection (INF, arrow). Cumulative presses required to obtain infusions on the progressive ratio schedule a nhanced intake on both day 4 and days $8-12$ post-infection. * $p<0.05$, AMPH versus saline exposed; ** $p=0.01, \mathrm{AMPH}-$ exposed mock-infected versus remaining groups; by significant ANOVA followed by LSD tests. $n=6-9 /$ group. c, Location of the injection cannula tips for rats included in the data analyses as described in Figure $2 c$.

motor response was completely abolished in the HSV-CaMKII $\alpha$ K42M-infected animals, not only on day 4 (Fig. $2 a$ ) but also on day 8 post-infection (Fig. $2 b$ ), again a time point when both CaMKII $\alpha$ expression and T286 phosphorylation had returned to baseline levels (Fig. 1b,c). Significant effects of exposure (day 4, $F_{(1,21)}=6.30, p<0.05$; day $\left.8, F_{(1,21)}=4.15, p=0.054\right)$ and infection $\left(\right.$ day $4, F_{(1,21)}=9.20, p<0.01$; day $8, F_{(1,21)}=4.43, p<$ 0.05 ) were detected on both test days. Thus, we next assessed the effect of transient CaMKII inhibition on the enhanced amphetamine intake observed following amphetamine exposure (Vezina et al., 2002; Vezina, 2004). Rats were again randomly assigned to four groups based on condition of exposure (amphetamine or saline) and infection (bilateral NAcc shell HSV-CaMKII $\alpha$ K42M or mock infection). As expected (Vezina et al., 2002), rats exposed to amphetamine and given the opportunity to selfadminister the drug intravenously worked significantly more and as a result obtained more infusions compared with salineexposed controls (Fig. 3; day -1 pre-infection, exposure, $\left.F_{(1,28)}=5.41, p<0.05\right)$. However, the day following infection through day 4 post-infection when expression of the transgene was maximal, amphetamine-exposed rats infected with HSVCaMKII $\alpha$ K42M no longer displayed enhanced amphetamine intake, obtaining the same number of infusions as saline-exposed rats and significantly fewer than mock-infected amphetamineexposed rats (Fig. 3; day 4 post-infection, exposure, $F_{(1,28)}=3.58$, $\left.p=0.07 ; \mathrm{E} \times \mathrm{I}, F_{(1,28)}=6.69, p<0.05\right)$. Importantly, this 
reversal of enhanced amphetamine self-administration was maintained for the full $12 \mathrm{~d}$ of testing post-infection and thus again outlasted the transient interference with CaMKII signaling achieved by HSV-CaMKII $\alpha$ K42M (Fig. 3; days 8-12 postinfection, $\left.\mathrm{E} \times \mathrm{I}, F_{(1,25)}=4.09, p=0.05\right)$.

\section{Discussion}

Expressing a dominant-negative form of CaMKII $\alpha$ (K42M) that transiently inhibits CaMKII activity in NAcc shell neurons persistently blocked the expression of two major manifestations of sensitization by amphetamine. As expected, previously exposing rats to amphetamine led to sensitized locomotor responding to a challenge injection of the drug and, in a separate group of rats, enhanced drug intake under a PR schedule of reinforcement (Vezina et al., 2002; Vezina, 2004). Transiently inhibiting CaMKII activity in the NAcc shell of these rats blocked these manifestations of sensitization and continued to do so long after expression of the transgene had dissipated, indicating that continued uninterrupted CaMKII activation is necessary for their maintenance. Previous studies suggested that CaMKII activity in the NAcc shell is required for the expression of stimulant sensitization (Pierce and Kalivas, 1997; Pierce et al., 1998; Loweth et al., 2008) and cocaine-induced reinstatement (Anderson et al., 2008). However, these previous studies tested the pharmacological inhibitor KN-93 that is known to affect not only CaMKII and other protein kinases but also to inhibit L-type $\mathrm{Ca}^{2+}$ channels, rendering an interpretation of results that focuses specifically on CaMKII difficult. The use of HSV-mediated delivery of a CaMKII $\alpha$ mutant in the present experiments circumvented these shortfalls. Importantly, the present study is the first to unequivocally demonstrate that transiently inhibiting CaMKII activity in the NAcc shell can lead to the persistent and selective reversal of enhanced behavioral response to amphetamine. Thus, the evidence reported here identifies CaMKII and the signaling pathways it initiates as attractive therapeutic targets for the treatment of substance abuse.

CaMKII regulates long-term potentiation (LTP) of synaptic strength, a form of neuronal plasticity thought to underlie both physiological and addiction-related maladaptive learning and memory (Loweth et al., 2010; Coultrap and Bayer, 2012). Transient interference with CaMKII signaling has been shown to persistently reverse LTP when it specifically disrupts the CaMKII/ NMDA-type glutamate receptor complex (Buard et al., 2010; Sanhueza et al., 2011). CaMKII mediates LTP by increasing both the number and the conductance of synaptic AMPA-type glutamate receptors (Coultrap and Bayer, 2012), the latter by phosphorylating their GluA1 subunit at S831 (Derkach et al., 1999; Kristensen et al., 2011). As normal LTP and LTP-induced GluA1 S831 phosphorylation require NMDA receptor-bound CaMKII (Barria and Malinow, 2005; Halt et al., 2012) and the CaMKII $\alpha$ K42M mutation disrupts this binding (O'Leary et al., 2011), we examined the GluA1 S831 phosphorylation state in our animals. Indeed, previous exposure to amphetamine produced a sustained increase in GluA1 S831 phosphorylation in the NAcc shell, as reported previously (Loweth et al., 2010), and it was persistently reversed by transient CaMKII $\alpha$ K42M expression in this site. Thus, while the interference with CaMKII signaling was transient, its effect on at least one important downstream mediator persisted, which may have contributed to the persistent reduction in the enhanced behavioral output normally observed in amphetamine sensitized rats. While GluA1 S831A mutant mice do not show impairments in hippocampal LTP or LTD (Lee et al., 2010), they do show deficits in responding for a conditioned reinforcer (Crombag et al., 2008). Alternatively, an AMPA receptor independent effect of CaMKII $\alpha$ on A-type potassium currents was recently proposed to also contribute to behavioral sensitization by cocaine (Kourrich et al., 2012).

Notably, CaMKII inhibition affected only the enhanced locomotor response and self-administration observed in rats previously exposed to amphetamine. HSV-CaMKII $\alpha$ K42M and mock-infected rats previously exposed to saline showed the same basal levels of amphetamine-induced locomotion and amphetamine intake throughout testing. These results indicate that continued uninterrupted CaMKII signaling in the NAcc shell is necessary specifically to maintain enhanced drug intake observed in individuals that have been repeatedly exposed to the drug but not for the initial basal intake seen before drug exposure. Although further characterization of the molecular mechanisms underlying these effects awaits further study, the results reported here clearly demonstrate that transient inhibition of CaMKII provides a viable therapeutic strategy to persistently reverse addiction-related behaviors.

\section{References}

Anderson SM, Famous KR, Sadri-Vakili G, Kumaresan V, Schmidt HD, Bass CE, Terwilliger EF, Cha JH, Pierce RC (2008) CaMKII: a biochemical bridge linking accumbens dopamine and glutamate systems in cocaine seeking. Nat Neurosci 11:344-353. CrossRef Medline

Barria A, Malinow R (2005) NMDA receptor subunit composition controls synaptic plasticity by regulating binding to CaMKII. Neuron 48:289-301. CrossRef Medline

Bayer KU, De Koninck P, Leonard AS, Hell JW, Schulman H (2001) Interaction with the NMDA receptor locks CaMKII in an active confirmation. Nature 411:801-805. CrossRef Medline

Bayer KU, LeBel E, McDonald GL, O’Leary H, Schulman H, De Koninck P (2006) Transition from reversible to persistent binding of CaMKII to postsynaptic sites and NR2B. J Neurosci 26:1164-1174. CrossRef Medline

Buard I, Coultrap SJ, Freund RK, Lee YS, Dell'Acqua ML, Silva AJ, Bayer KU (2010) CaMKII "autonomy" is required for initiating but not for maintaining neuronal long-term information storage. J Neurosci 30:82148220. CrossRef Medline

Carlezon WA Jr, Neve RL (2003) Viral-mediated gene transfer to study the behavioral correlates of CREB function in the nucleus accumbens of rats. Methods Mol Med 79:331-350. Medline

Coultrap SJ, Bayer KU (2012) CaMKII regulation in information processing and storage. Trends Neurosci 35:607-618. CrossRef Medline

Crombag HS, Sutton JM, Takamiya K, Lee HK, Holland PC, Gallagher M, Huganir RL (2008) A necessary role for GluR1 serine 831 phosphorylation in appetitive incentive learning. Behav Brain Res 191:178-183. CrossRef Medline

Derkach V, Barria A, Soderling TR (1999) $\mathrm{Ca}^{2+} /$ calmodulin-kinase II enhances channel conductance of alpha-amino-3-hydroxy-5-methyl-4isoxazolepropionate type glutamate receptors. Proc Natl Acad Sci U S A 96:3269-3274. CrossRef Medline

Gao L, Blair LA, Marshall J (2006) CaMKII-independent effects of KN93 and its inactive analog KN92: reversible inhibition of L-type calcium channels. Biochem Biophys Res Commun 345:1606-1610. CrossRef Medline

Garic A, Flentke GR, Amberger E, Hernandez M, Smith SM (2011) CaMKII activation is a novel effector of alcohol's neurotoxicity in neural crest stem/progenitor cells. J Neurochem 118:646-657. CrossRef Medline

Halt AR, Dallapiazza RF, Zhou Y, Stein IS, Qian H, Juntti S, Wojcik S, Brose N, Silva AJ, Hell JW (2012) CaMKII binding to Glun2B is critical during memory consolidation. EMBO J 31:1203-1216. CrossRef Medline

Kourrich S, Klug JR, Mayford M, Thomas MJ (2012) AMPAR-independent effect of striatal $\alpha$ CaMKII promotes the sensitization of cocaine reward. J Neurosci 32:6578-6586. CrossRef Medline

Kristensen AS, Jenkins MA, Banke TG, Schousboe A, Makino Y, Johnson RC, Huganir R, Traynelis SF (2011) Mechanism of $\mathrm{Ca}^{2+} /$ calmodulindependent kinase II regulation of AMPA receptor gating. Nat Neurosci 14:727-735. CrossRef Medline

Kühl M, Sheldahl LC, Malbon CC, Moon RT (2000) $\mathrm{Ca}^{2+} /$ calmodulin- 
dependent protein kinase II is stimulated by Wnt and Frizzled homologs and promotes ventral cell fates in Xenopus. J Biol Chem 275:12701-12711. CrossRef Medline

Lee HK, Takamiya K, He K, Song L, Huganir RL (2010) Specific roles of AMPA receptor subunit GluR1 (GluA1) phosphorylation sites in regulating synaptic plasticity in the CA1 region of the hippocampus. J Neurophysiol 103:479-489. CrossRef Medline

Li G, Hidaka H, Wollheim CB (1992) Inhibition of voltage-gated Ca2+ channels and insulin secretion in HIT cells by the Ca2+/calmodulindependent protein kinase II inhibitor KN-62: comparison with antagonists of calmodulin and L-type Ca2 + channels. Mol Pharmacol 42:489498. Medline

Lisman J, Yasuda R, Raghavachari S (2012) Mechanisms of CaMKII action in long-term potentiation. Nat Rev Neurosci 13:169-182. CrossRef Medline

Loweth JA, Baker LK, Guptaa T, Guillory AM, Vezina P (2008) Inhibition of CaMKII in the nucleus accumbens shell decreases enhanced amphetamine intake in sensitized rats. Neurosci Lett 444:157-160. CrossRef Medline

Loweth JA, Singer BF, Baker LK, Wilke G, Inamine H, Bubula N, Alexander JK, Carlezon WA Jr, Neve RL, Vezina P (2010) Transient overexpression of $\alpha-\mathrm{Ca}^{2+} /$ calmodulin-dependent protein kinase II in the nucleus accumbens shell enhances behavioral responding to amphetamine. J Neurosci 30:939-949. CrossRef Medline

Neve RL, Howe JR, Hong S, Kalb RG (1997) Introduction of the glutamate receptor subunit 1 into motor neurons in vitro and in vivo using a recombinant herpes simplex virus. Neuroscience 79:435-447. CrossRef Medline

O’Leary H, Liu WH, Rorabaugh JM, Coultrap SJ, Bayer KU (2011) Nucleotides and phosphorylation bi-directionally modulate $\mathrm{Ca}^{2+}$ / calmodulin-dependent protein kinase II (CaMKII) binding to the $\mathrm{N}$-methyl-D-aspartate (NMDA) receptor subunit to GluN2B. J Biol Chem 286:31272-31281. CrossRef Medline

Paxinos G, Watson C (2005) The rat brain in stereotaxic coordinates. Amsterdam: Elsevier Academic.
Pierce RC, Kalivas PW (1997) Repeated cocaine modifies the mechanism by which amphetamine releases dopamine. J Neurosci 17:3254-3261. Medline

Pierce RC, Quick EA, Reeder DC, Morgan ZR, Kalivas PW (1998) Calciummediated second messengers modulate the expression of behavioral sensitization to cocaine. J Pharmacol Exp Ther 286:1171-1176. Medline

Robinson TE, Berridge KC (1993) The neural basis of drug craving: an incentive-sensitization theory of addiction. Brain Res Brain Res Rev 18: 247-291. Medline

Sanhueza M, Fernandez-Villalobos G, Stein IS, Kasumova G, Zhang P, Bayer KU, Otmakhov N, Hell JW, Lisman J (2011) Role of the CaMKII/ NMDA receptor complex in the maintenance of synaptic strength. J Neurosci 31:9170-9178. CrossRef Medline

Singer BF, Loweth JA, Neve RL, Vezina P (2010) Transient viral-mediated overexpression of alpha-calcium/calmodulin-dependent protein kinase II in the nucleus accumbens shell leads to long-lasting functional upregulation of alpha-amino-3-hydroxyl-5-methyl-4-isoxazole-propionate receptors: dopamine type-1 receptor and protein kinase A dependence. Eur J Neurosci 31:1243-1251. CrossRef Medline

Suto N, Tanabe LM, Austin JD, Creekmore E, Pham CT, Vezina P (2004) Previous exposure to psychostimulants enhances the reinstatement of cocaine seeking by nucleus accumbens AMPA. Neuropsychopharmacology 29:2149-2159. CrossRef Medline

Vezina P (2004) Sensitization of midbrain dopamine neuron reactivity and the self-administration of psychomotor stimulant drugs. Neurosci Biobehav Rev 27:827-839. CrossRef Medline

Vezina P, Lorrain DS, Arnold GM, Austin JD, Suto N (2002) Sensitization of midbrain dopamine neuron reactivity promotes the pursuit of amphetamine. J Neurosci 22:4654-4662. Medline

Wayman GA, Tokumitsu H, Davare MA, Soderling TR (2011) Analysis of CaM-kinase signaling in cells. Cell Calcium 50:1-8. CrossRef Medline

Xiao C, Yang BF, Song JH, Schulman H, Li L, Hao C (2005) Inhibition of CaMKII-mediated c-FLIP expression sensitizes malignant melanoma cells to TRAIL-induced apoptosis. Exp Cell Res 304:244-255. CrossRef Medline 